\title{
Una propuesta de los presupuestos teóricos del personalismo literario para la enseñanza
}

A proporsal of the theoretical reasons of
literary personalism for teaching

Jorge Mario Cabrera Valverde Consejo Nacional de Rectores (CONARE)

Costa Rica conare@ac.cr

\begin{abstract}
Resumen
En esta propuesta se analizarán los presupuestos teóricos del personalismo literario y su vinculación con el personalismo filosófico y con la educación. En los primeros se presenta lo que Alfonso López Quintás denomina los ocho niveles de realidad y de conducta. De estos niveles cuatro son positivos y cuatro son negativos. Nos centraremos en los positivos. A partir de ellos se valorarán obras literarias con más elementos que los utilizados por análisis literarios convencionales, y se podrán observar algunas aplicaciones a la enseñanza.
\end{abstract}

Palabras claves: crítica, personalismo, análisis literario, educación, Alfonso López Quintás. 


\begin{abstract}
This proposal analizes the theoretical suppositions of Literary Personalism, and their relations to philosophical Personalism and Education. The first ones present what López Quintás calls the eight levels of reality and conduct. These levels are divided into four positive and four negative levels. Our proposal will use only the positive ones. The result is an estimation of literary works that utilizes much more elements for the analysis than those provided by literary criticism based upon formalism, or other theories, and will appear some applications to Education.
\end{abstract}

Keywords: Literary criticism, personalism, literary analysis, education, Alfonso López Quintás.

\section{Introducción}

$\mathbf{N}$ os basaremos, sobre todo, en un escrito que presentamos en un congreso sobre personalismo hace un año ("Una propuesta para el marco teórico del personalismo literario". En revista Academia, Vol. 14, 2015. Versión digital)

Ya en la Poética de Aristóteles (384-322 a.C.) se proponen varios caminos para abordar un texto literario. Desde entonces a la actualidad se han presentado escuelas, críticas, teorías y análisis diversos según la denominación que les hayan dado los distintos estudiosos.

Dentro de todos los métodos literarios que se proponen para analizar un texto, quisiéramos presentar el personalismo literario, sin que ello signifique que se pretenda descalificar otros métodos o que no se pueda utilizar juntamente con ellos.

Con esta presentación de los presupuestos teóricos del personalismo literario, tratamos de contribuir a dar a conocer un medio análisis literario que no es tan utilizado como otros. Para ello, traeremos a colación ejemplos de obras literarias muy variadas y aplicaremos algunas propuestas de análisis del filósofo español Alfonso López Quintás (n. 1928).

\section{El método personalista en literatura}

Se trata de proponer un medio para interpretar, estudiar y profundizar en una obra narrativa. El intento que realiza López Quintás es el que llamó de una escuela creativa. Dicho autor sugiere distinguir los modos de realidad: el caso que presenta es el de un objeto, una persona o sujeto, un ámbito. Para él, una cosa no es totalmente opuesta a un ámbito. Por otra parte, lo que más se acerca a un ámbito es una persona. Dice, por ejemplo, "a estas realidades -como las personas- que abarcan cierto campo, que tienen poder de iniciativa, que pueden relacionarse con otras y enriquecerse mutuamente, las llamamos ámbitos de realidad, o bien escuetamente ámbitos" (Escuela de pensamiento 45). 
En literatura o en retórica se utiliza la figura de personificación para convertir en persona una cosa o un animal. Por el contrario, cosificar a una persona no es tratar de manera adecuada un ámbito.

En la obra citada, López Quintás explica por qué el piano puede ser un ámbito. Para ello, recurre a lo que llama experiencia reversible, algo parecido a un encuentro (Escuela de pensamiento 51-54). Al tocar un piano e interactuar con él, una persona lo trata como algo vivo: el piano contesta con sonidos y, si el que toca es un pianista, puede obtener obras musicales. De esta manera, se relaciona dos ámbitos y surge un nuevo ámbito (Cómo formarse 30).

López Quintás distingue entre significado y sentido. El ejemplo que muestra es el de una acción con un significado y varios sentidos: se puede tomar vino para acompañar una comida; puede también servir para brindar o para emborracharse Escuela de pensamiento 47).

Cuando se reúnen todas las características positivas que se puedan, se obtiene unidad en un personaje $y$, en lo que se refiere a una persona, también puede ir consiguiéndola. Si se obtienen experiencias negativas, la persona o el personaje se resquebrajan.

De acuerdo con López Quintás:

Al crear formas elevadas de unidad el hombre, que es un ser de encuentro según la ciencia actual, se desarrolla plenamente, alcanza su madurez, se hace plenamente libre, se pone en verdad, gana su verdadera identidad personal, adquiere su pleno sentido [...]. Esa plenitud de sentido suscrita en el ánimo del hombre sentimientos de alegría, entusiasmo, felicidad, amparo, paz, júbilo festivo (Escuela de pensamiento 56).

Tanto el lenguaje como el silencio pueden llevar al encuentro y a la creatividad. El lenguaje se utiliza en sentido amplio: lenguaje corporal, o por señas, o de alguna otra manera. Se espera que todo ello tenga respuestas para formar vínculos de convivencia (Escuela de pensamiento 57-63).

Para fomentar la unidad también pueden efectuar modo de encuentro valiosos; por ejemplo, obtener valores, expresarse a partir de relaciones entre personas o entre ámbitos o, tratando de integrar modos de realidad, ingresamos en un proceso de éxtasis. Si acaso sigo características negativas como ser egoísta, dominar o poseer, me induciré en un proceso de vértigo que va contra la unidad (Escuela de pensamiento 70-79).

\section{Aplicaciones del método}

Como ejemplo de educación en literatura, talvez dirigida a los alumnos más avanzados, se puede mencionar la obra Ana $\mathrm{Ka}$ renina de Tolstoi. La narración presenta a Ana, a su esposo Alejandro y al hijo de ambos, Sergio. Ana, de recta conducta a lo largo de varios años, se apasiona por un oficial del ejército, llamado Wronsky. Se podría decir que Ana se introduce en el vértigo a partir de entonces, aunque ya antes no ha cuidado de manera suficiente la distancia con Wronsky, que debería haber mantenido para ser fiel a su matrimonio. Ana termina yéndose con Wronsky, mientras que su esposo permanece en una actitud difna y se niega, por un lado, a otorgar el divorcio a 
Ana y, por otro, decide no dejar que ella visite a su hijo Sergio. Continuando con el desarrollo de la novela, Ana se ve rodeada de situaciones negativas, que no habrían ocurrido si no se hubiera decidido por el vértigo. (Tolstoi se introduce en la psicología del personaje y lo describe en muy diferentes situaciones). Al mantenerse en el vértigo, sin salir voluntariamente de él, Ana opta por suicidarse.

Si la novela hubiera terminado allí, quedaría en el lector una sensación muy negativa. Sin embargo. Tolsti la concluye con otro personaje: un campesino o terrateniente llamado Levin que, al final, logra casarse con la mujer que ama y que es correspondido, con lo cual ambos llevan una vida feliz. Esta historia es la antítesis de la de Ana y deja una enseñanza que el lector debe entresacar al modo de una moraleja.

Regresando a lo que presenta López Quintás: hay muchos tipos de vértigo que deben evitarse, tales como aislarse, dejarse llevar por la inercia o por la rutina, darse al libertinaje o a sentimientos no controlados, incurrir en mala fe, abandonarse a la imaginación, destruir, ser cruel, dominar, ser avaro, entregarse a los juegos de azar, ser envidioso o malamente curioso. En definitiva, estos actos pueden clasificarse como antivalores o defectos (Vértigo y éxtasis 47-74).

Por otra parte, López Quintás menciona también virtudes o actos buenos a los que el autor denomina éxtasis: hacer deporte, triunfar, alcanzar cumbres, saber apreciar la belleza o la interpretación dramática, amar a los demás, saber intelectualmente, la relación compositor y música (Vértigo y éxtasis 75-126).
Dirijámonos ahora hacia lo que López Quintás llama mirada profunda, con la que se podría abordar cualitativamente una obra. El autor señala que esa mirada tiene cuatro niveles positivos de conducta y de realidad: a) los objetos y su manejo; b) actitud creativa usando las relaciones de encuentro; c) buscar el ideal de unidad por medio de valores como la verdad, la bondad, la justicia, la belleza (nuestra vida será el valor más alto); y d) el nivel de lo espiritual, trascendente o religioso (La mirada 37).

A los estudiantes o alumnos habría que hacerles ver que, aunque consideren su propia religión como la verdadera, deben respetar a aquellos que tengan religión distinta, en atención a que se trata con seres humanos. Toda persona tiene derecho a vivir y practicar la religión que en conciencia considere verdadera. De aquí que también tenga que respetar a las demás personas que piensen de manera distinta.

Una aplicación de la mirada profunda en este último nivel puede ayudar a explicarnos más claramente. Un grabado de Durero respecto a la Natividad puede parecer, en un primer momento, a alguien superficial o desconocedor, como poco atractivo y sin gracia. Sin embargo, la mirada profunda es capaz de penetrar en lo que representa: al Dios hecho niño, que ha descendido a la tierra para redimirnos.

López Quintás recomienda que el lector dialogue o juegue con la obra literaria. Debe penetrar en ella, tratar de profundizarla hasta lograr ver, volver a desarrollar o a crear qué razones y motivos llevaron al autor a escribirla. Se espera 
que así se llegue a entender mejor a los personajes (Literatura francesa 58 y 69 ; La mirada 38).

En Crimen y castigo de Dostoyevski (1821-1881), se puede clasificar entre los locos al personaje Raskolnikof, que había matado a dos mujeres indefensas, pero, también podríamos ponernos en su lugar, tanto como en el autor. Por ejemplo, uno podría preguntarse qué haría si es sorprendido por otra persona después de matar a alguien. Apliquemos a Rakolnikof lo que hemos visto sobre vértigo, y posiblemente nos expliquemos mejor su conducta para comprender por qué cometió el segundo crimen. (Ya es conocida en Dostoyevski su manera de describir psicológicamente a sus personajes).

En El Rey Lear de Shakespeare (15641616), dicho rey tenía la ilusión de que sus hijas herederas fueran las que cuidaran de él ahora que estaba viejo y sin bienes. Shakespeare, a lo largo de la obra, nos muestra cómo, al caer en el vértigo de la avaricia, las hijas procuras deshacerse del padre. La obra original parece ser de Godofredo de Monmouth (S. XII d.C.), que la incluyó en su Historia de los Reyes de Britania, y que el Rey Lear habría existido varios cientos de años antes de Cristo. Sin embargo, ahora se considera dicha historia llena de fantasía. Nuevamente, la historia del Rey Lear parece, más bien, una narración propia para dejar una enseñanza.

En Antígona de Sófocles (S. V a.C.), un personaje, Creón, el tirano, defiende la ley positiva, mientras que Antígona está a favor de la ley natural. Se podría decir que es un debate muy actual, cuando los defensores del iuspositivismo se imponen sobre la ley natural en muchos países. ¿Cómo saber quién de los dos personajes está en vértigo? ¿Creón o Antígona? El lector tendrá que ponerse en el lugar correspondiente a cada uno para saberlo, y, posiblemente, no baste adoptar una posición, sin antes haber profundizado en el origen de cada uno de esos tipos de leyes.

\section{Según López Quintás (La mirada 65):}

La mirada profunda nos permite ver cada uno de los pormenores de una obra literaria o musical y, a la vez, el conjunto de la misma. Podemos ver todo sinópticamente por la profunda razón de que el conjunto de la obra está inspirando y configurando cada uno de los pormenores y expresa en ellos.

En El asno de oro de Apuleyo (125-180 d.C.), el personaje Lucio se deja llevar por el vicio y por una curiosidad malsana (cae en vértigo), queda transformado en burro $\mathrm{y}$, después de múltiples humillaciones y de buscar la misericordia (y el cuarto nivel, espiritual), recobra su forma humana. En este caso tenemos un llamado a mantenerse en la virtud para no caer en el vicio y, más tarde, en los castigos o consecuencias que conlleva.

Goethe (1749-1832), en la primera parte de Fausto, el personaje del mismo nombre se deja seducir por el vértigo al que le invita Mefistófeles, y con él arrastra a Margarita, la cual es condenada a muerte. Fausto intenta sacarla de la cárcel en que se encuentra, momento en el que ella recibe una luz proveniente del nivel espiritual y se salva. En la segunda parte, es Margarita quien intercede por la 
salvación de Fausto. En esta ocasión tenemos el anuncio de alguien que se arrepiente antes de morir.

En la primera parte de Don Quijote de la Mancha, Cervantes (1547-1616) introduce una novela corta llamada El curioso impertinente. En ella, Anselmo ingresa en vértigo al dejarse llevar por una curiosidad inútil: trata de poner a prueba a su esposa, indicando a su amigo Lotario que la corteje para ver si ella es fiel. Lo que consigue es que su esposa y Lotario se hagan amantes. El lector, con mirada profunda, reconoce lo necio de Anselmo y, si se pusiera en vez de Lotario, probablemente optaría por negarse a participar en semejante lance.

López Quintás analiza también varias obras literarias en su escrito Cómo formarse en ética a través de la literatura. Veamos cómo enfrenta La metamorfosis de Kafta (1883-1924). Antes haremos un pequeño resumen del argumento: Gregorio, que trabaja en el comercio, al despertar un día, se encuentra convertido en insecto. (El lector, desde ese momento, empezaría a tratar de clasificar la obra como algo cómico, una ficción, o se imagina que más bien Kafka intenta comunicarnos algo).

Acaecida la metamorfosis, Gregorio sigue pensando como una persona. Lo mismo ocurre con su querer y sentirse como humano. Al principio, el resto de la familia lo sigue tratando como persona aunque sigan viendo un insecto; pero, Gregorio ya perdió la capacidad de actuar creadoramente. Luego, la familia modifica el espacio en que se mueve Gregorio, en cuanto que lo empiezan a tratar como insecto, y no se esfuerzan para ayudarle en que se recupere como hombre. Gregorio confía en que su hermana Grete llegue a ser violinista y, por eso, lleno de ilusión, trabajaba para ayudar en la casa. Al final, es Grete quien convence a los padres para que consideren a Gregorio como cosa y ya no como persona. Gregorio se desalienta y termina muriendo (Cómo formarse 67-69).

La obra incluye, entonces, una enseñanza, además de valores estéticos: no hay que tratar a una persona como si fuera solo un productor de bienes o de dinero. Se le debe facilitar un medio en el que se desarrolle en cuanto persona y pueda ser constructivo. Esto puede considerarse como una magnífica imagen que Kafka nos presenta.

Asimismo, en Cómo formarse en ética (86), López Quintás nos señala que "la literatura tiene por cometido clarificar los aspectos de la realidad que se escapan a una visión superficial". Siguiendo esta visión más profunda, nos deja un estudio de La Celestina de Fernando de Rojas (1465-1541). Para ello añade el juego y el encuentro al concepto de belleza. Veamos lo que dice:

La fuente de belleza literaria no radica solamente en las condiciones estilísticas del autor. Pende, sobre todo, de la plasmación expresiva de los diversos mundos humanos, de su articulación mutua, de los mundos nuevos que surgen merced a la intercomunicación. El análisis literario, si ha de ser auténtico e integral, no puede limitarse a modos de lectura dirigidos en exclusiva a destacar los aspectos formales de las obras. Debe poner al descubierto el contenido verdadero de éstas, no su mero argumento, sino el ámbito o ámbitos de vida que el 
autor desea plasmar. Los grandes literarios desean encarnar en sus obras los aspectos lúdicos de la existencia humana: armonías y conflictos, pasiones y luchas, deseos y frustraciones, mundos que se desmoronan y colisionan entre sí. Este tipo de realidades y acontecimientos sólo se conocen por vía de experiencia comprometida, de juego co-creador. La realización de este juego es la raíz de la más honda belleza literaria (87).

Volvamos ahora a La Celestina (o Tragicomedia de Calixto y Melibea): la obra nos muestra algunas relaciones eróticas que acontecen junto con muertes violentas. Por ejemplo, Calixto visita a Melibea, que es su amante. Cuando se retira, sufre un accidente en la escalera y muere al caer. Enterada de ello, Melibea se va a lo alto de una torre, acepta ante su padre la falta cometida y, lanzándose desde arriba, también cae y muere. Por otra parte, Celestina había sido muerta por los siervos de Calixto porque no les había otorgado su parte de lo que Calixto le había dado facilitar el encuentro con Melibea. En definitiva, la mirada profunda descubre otra enseñanza: delata "ante los hombres de su época, los riesgos que encierra la entrega al vértigo del erotismo" (López Quintás, Cómo formarse 88), o de la avaricia.

La obra de teatro Esperando a Godot de Samuel Beckett (1906-1989) contiene solo cinco o seis personajes. Es una muestra del llamado teatro del absurdo. En Europa se dio una época llamada neorrealismo, correspondiente a un periodo posterior a la Segunda Guerra Mundial, que llevó a una cierta pérdida de esperanza. De esa época son la película Ladrón de bicicletas, en Italia, y la novela Nada de Laforet, en
España. En Esperando a Godot también aparece esa falta de esperanza.

Veamos cómo López Quintás analiza Esperando a Godot, una especie de tragicomedia. La obra inicia con dos personajes vagabundos: Vladimir y Estragón están esperando a Godot, porque él tendría la manera de salvarlos de su situación desesperada. Estos vagabundos no poseen la creatividad necesaria para salir de ese atolladero; pero, Godot no llega; a lo más, anuncia que llegará al día siguiente, sin cumplirlo. En el primer acto, lo más representativo es un árbol seco, símbolo de la situación en que están los dos vagabundos. En el segundo acto, el árbol se llena de hojas. La obra parece decirnos que un vegetal está en mejor condición que un ser racional, ya que no piensa, ni, menos, busca suicidarse (Literatura francesa 437 492 y Cómo formarse 229-262).

Dejemos, por el momento, las obras de violencia y pasemos a otros enfoques. Nos referimos a El principio de Saint-Exupéry (1900-1944). López Quintás lo incluye entre sus ejemplos (Literatura francesa 229-283 y Cómo formarse 197-228).

Recordemos un poco el argumento: un piloto de avión sufre una avería y desciende en un desierto para reparar su nave. Llega un niño y le pide que le dibuje un cordero. El piloto se muestra reacio y el niño llora. El piloto intenta dibujarle un par de corderos que el niño rechaza. Finalmente, dibuja una caja con varios agujeros laterales que simulan respiraderos. El niño goza con este último porque le parece creativo: se puede imaginar el cordero como desee. 
Luego, el niño explica al piloto que se encontraba en un asteroide para buscar amigos. Como no dio con ellos (excepto con un farolero), ya que no efectuaban relaciones de encuentro ni tenían creatividad, se va a llamar a los hombres para ver si logra conseguir más amigos; pero, no le responden. Un zorro se encuentra con el niño y le enseña el valor que tienen los seres, la amistad y el conocimiento. El niño regresa donde está el piloto para buscar agua juntos, hasta que dan con ella. El niño solicita al piloto que siga reparando su nave para que pueda volver a su casa. A su vez, el niño irá a un planeta en donde le brillarán las estrellas. El niño se deja morder por una serpiente desaparece. Por último, el piloto regresa a su tierra.

López Quintás nos comenta sobre la estética de esta obra:

Con un estilo directo y transparente, Saint-Exupéry contribuyó a configurar un modo de literatura realista y poética a la par, cargada de fuerza simbólica y poder de penetración en la realidad más honda. Esta conjunción fue posible, sin duda, porque Saint-Exupéry tenía un sexto sentido para captar los fenómenos ambitales y descubrir la fecundidad del juego. Al plasmar ámbitos, surge el lenguaje poético $\mathrm{y}$, al interferirlos, se alumbra la luz del símbolo. Simbolismo y poesía no alejan de la realidad; la revelan, ponen brillantemente de manifiesto que el hombre alcanza las cotas más altas de su existencia cuando cumple las condiciones del auténtico encuentro. Las obras de Saint-Exupéry están tejidas de encuentros logrados y encuentros fallidos. Si adivinamos las razones profundas de tal fracaso y tal éxito, poseeremos una clave para descifrar el secreto del singular poder que muestran los escritos de Saint-Exupéry para transmitir la experiencia de la vida en un lenguaje denso y noble, que se preocupa por adquirir la belleza formal sin perder la inmediatez jugosa del reportaje y la elevación característica de la penetración filosófica (Cómo formarse 204).

Volvamos al texto de El principito. El piloto decide jugar con el niño y le pregunta por un dibujo que este último ha efectuado y que se parece a un sombrero. La jugada del niño es correcta, ya que contesta que es una boa que se comió un elefante. Seguidamente continúa el pasaje ya visto sobre el cordero. La iniciativa es ahora del niño. Tanto el piloto como el niño juegan creativamente.

En el cuento, el niño no está objetivado, ya que aparece en cualquier momento $\mathrm{y}$, al irse, desaparece. Por el contrario, al piloto se le puede localizar con coordenadas y desea que todo sea así; es decir, el ser humano quisiera objetivar todo para estudiarlo, investigarlo. Esto es lo que todas persona -mejor, cualquiera con mentalidad científico-experimental- quisiera hacer. De esta manera, el piloto conserva capacidad de asombro ante lo inesperado: sabe crear ámbitos y, así ingresar en el nivel lúdico como ya hemos visto. Con su avión crea ámbitos y lo siente parte de sí mismo. Niño y piloto, ambos con posición creativa, se van conociendo uno al otro. El principito tenía una flor en su asteroide y pensaba que era única aunque un tanto vanidosa. Pero, luego de haber visto muchas flores, se percata de que su flor no es única y se pone triste. La sabiduría del zorro le lleva a darse cuenta de que la unicidad se encuentra en las relaciones de amistad que 
se han generado. El zorro supone que domesticar es crear lazos. Con ello se obtendría depender mutuamente el uno del otro. El principito asegura que solo con el corazón se ve bien y que los ojos no llegan a captar lo esencial. De aquí que los amigos respondan si se les trata en una relación personal de convivencia. Niño y piloto profundizan su amistad al salir al desierto a buscar agua con la que sobrevivan. Dan con pozo y beben agua. Les sirve más al corazón que a la sed. Luego, cada uno regresa a su hogar con el conocimiento y la práctica, la importancia de establecer relaciones o lazos con otras personas (Literatura francesa 22-283).

López Quintás resume la enseñanza en el siguiente párrafo:

A través de un severo aprendizaje y un lento proceso de purificación, el principito y el piloto han logrado la forma eminente de unión personal que llamamos amistad. Seguidamente, en virtud de la fidelidad que implica el amor auténtico, se ven instados a renunciar al halago de la inmediatez física para restaurar, en un plano de mayor autenticidad, la vinculación a los seres de su entorno hogareño [...]. Merced al proceso de esforzada depuración espiritual a que ambos se han sometido, el reencuentro tendrá lugar ahora en nivel lúdico, nivel creador de auténticos ámbitos. La madurez de espíritu nos permite establecer vínculos personales muy intensos a través de los diversos elementos que sirven de vehículo a la unión. Entre tales elementos figuran los rasgos de carácter que uno puede considerar defectuosos. Todo $-\mathrm{lo}$ positivo y, lo en apariencia, negativoqueda transfigurado y hecho transparente cuando es puesto en tensión dinámica por la generosidad de un amor oblativo. Esta transfiguración hace posible la actitud de fidelidad que mantiene la relación de presencia y encuentro a través de los cambios que provoca el tiempo en los seres que se aman (Cómo formarse 227).

\section{Conclusión}

López Quintás presenta un método para introducirse, de una manera no tradicional, en las obras de arte. No trata de sustituir otros métodos de análisis literario, sino complementarlos y reorientarlos de alguna forma para que no desaparezca el autor o el lector. Se debe resaltar cómo incorpora los valores de los personajes de la trama o de la obra a su análisis y cómo se puede aplicar en la enseñanza.

\section{Referencias}

Apuleyo, Lucio. El asno de oro. Trad. Vicente López Soto. Barcelona: Juventud, 1984. Impreso.

Aristóteles. El arte poética. Trad. José Goya y Muniain. Sexta edición. Madrid: Espasa-Calpe. 1979. Impreso.

Aristóteles. Retórica. Trad. Antonio Tovar. Cuarta edición. Madrid: Centro de Estudios Constitucionales, 1990. Impreso.

Beckett, Samuel. Esperando a Godot. Trad. Ana María Moix. Barcelona. Tusquets Editores, 2007. Impreso.

Cabrera Valverde, Jorge Mario. "Una propuesta para el marco teórico del personalismo literario". En Rev. Academia. Vol. 14 (2015). Web. Versión digital en: http://erevistas. saber.ula.ve/index.php/academia/ article/view/7606. 
Cervantes, Miguel de. El ingenioso hidalgo don Quijote de la Mancha. Octava edición. Madrid: Espasa-Calpe, 2005. Impreso.

Dostoyevski, Fiódor. "Crimen y castigo". En: Obras inmortales. Trad. Ramón Ledezma Miranda, F. Ramón y G. Vázquez. Madrid: EDAF-Edesco, 1999, 807-1323. Impreso.

Goethe, Wolfgang von. Fausto. Trad. José Roviralta Borell. Barcelona: Océano, 1981. Impreso.

Gómez Redondo, Fernando. La crítica literaria del siglo $X X$. Madrid: EDAF, 1996. Impreso.

Kafka, Franz. La metamorfosis s.t. Reimpresión. Madrid: Alianza Editorial, 2006. Impreso.

Kayser, Wolfgang. Interpretación y análisis de la obra literaria. Trad. María D. Mouton y Vicente García Yebra. Cuarta edición. Séptima reimpresión. Madrid: Gredos, 1992. Impreso.

López Quintás, Alfonso. Cómo formarse en ética a través de la literatura: Análisis estético de obras literarias. Segunda edición. Madrid: Rialp, 1994. Impreso.

. Escuela de pensamiento y creatividad: Un proyecto educativo en cinco cursos. Madrid: Asociación para el Progreso de las Ciencias Humanas, 1996. Impreso.

. "La mirada profunda: Sus condiciones y su fecundidad". En Ospina, Helena y Gabriel Quesada Mora (eds.). Literatura y personalismo: Una mirada profunda. San José: Promesa, 2014, 35-82. Impreso.
- Literatura francesa del siglo $X X$. San José: Promesa, 2011. Impreso. - Vértigo y éxtasis: Bases para una vida creativa. Madrid: Asociación para el Progreso de las Ciencias Humanas, 1987. Impreso.

Muñoz García, Juan José. "Entender el cine en clave personalista". En: Burgos, Juan Manuel, José Luis Cañas y Urbano Ferrer. (eds.). Hacia una definición de la filosofía personalista. San José Promesa, 2008. Impreso.

Rojas, Fernando de. La Celestina. Ed. Santiago López Ríos. Barcelona: Debolsillo, 2002. Impreso.

Saint-Exupéry, Antoine de. El principio. Trad. María de los Ángeles Porrúa. Vigésimo novena edición. México: Porrúa, 2007. Impreso.

Selden, Raman. La teoría literaria contemporánea. Trad. Juan Gabriel López Guix. Segunda edición. Tercera reimpresión. Barcelona: Ariel, 1998. Impreso.

Shakespeare, William. "El rey Lear". En: Teatro selecto. Vol. II. Trad. Ángel Pujante y Salvador Oliva. Madrid: Librerías Troa, 2008, 1507-1618. Impreso.

Sófocles. "Antígona”. En: Tragedias completas. Trad. José Vara Donado. Decimosexta edición. Madrid: Cátedra, 2011, 139-194. Impreso.

Tolstoi, León. Ana Karenina. Trad. Leoncio Surena y Alfredo Santiago. Barcelona: Bruguera, 1983. Impreso.

Wellek, René y Austin Warren. Teoría literaria. Trad. José María Gimeno. Cuarta edición. Sexta reimpresión. Madrid: Gredos, 1993. Impreso. 